\title{
4. AOTrauma-Kniekurs 2018 in Hamburg St. Georg ein voller Erfolg!
}

Karl-Heinz Frosch, Michael Raschke

\author{
Am 24. und 25. April 2018 fand in Hamburg St. Georg der 4. AOTrauma-Kniekurs unter \\ der Leitung von Prof. Dr. K.-H. Frosch und Prof. Dr. M. Raschke statt. Der Kurs richtete \\ sich vor allem an erfahrene Unfallchirurgen und Orthopäden und war mit 63 Teil- \\ nehmern und einer langen Warteliste bereits Monate vor Kursbeginn ausgebucht.
}

Als Referenten und Instruktoren waren hochkarätige Experten aus ganz Deutschland eingeladen, um ihre Erfahrungen und aktuelle Trends in der Frakturversorgung und der knienahen Osteotomie zu präsentieren. Vormittags fanden jeweils Vorträge, Fallpräsentationen und Expertendiskussionen statt. Nachmittags folgte jeweils der „Hands-On Workshop“ an humanen Kadaverkniegelenken. Dabei wurden die Zugänge für die Frakturversorgung (1. Tag) und knienahe Osteotomien (2. Tag) jeweils von erfahrenen Operateuren voroperiert und den Teilnehmern an humanen Kniepräparaten demonstriert. Die Teilnehmer bekamen dann die Möglichkeit, die Eingriffe selbst durchzuführen. Dabei konnten neben sämtlichen Zugängen am Kniegelenk auch die Osteotomien an Femur und Tibia am Humanpräparat realitätsnah geübt werden. Abschließend konnten die osteosynthetischen Versorgungen radiologisch kontrolliert werden.

Der Kurs wurde von allen Teilnehmern durchweg positiv und als überdurchschnittlich gut evaluiert. Insbesondere die praktischen Übungen sind mit einer Durchschnittsnote von 1,33 erwähnenswert. Alle Teilnehmer konnten den Kurs weiterempfehlen.

Aufgrund der positiven Resonanz wird 2019 wieder ein AOTrauma-Kniekurs stattfinden. Der Termin ist vom 23.09-26.09.2019, der Veranstaltungsort Münster.

Prof. Dr. Karl-Heinz Frosch, Asklepios St. Georg, Hamburg Prof. Dr. Michael J. Raschke, Universitätsklinikum Münster E-Mail: michael.raschke@ukmuenster.de

Bibliografie

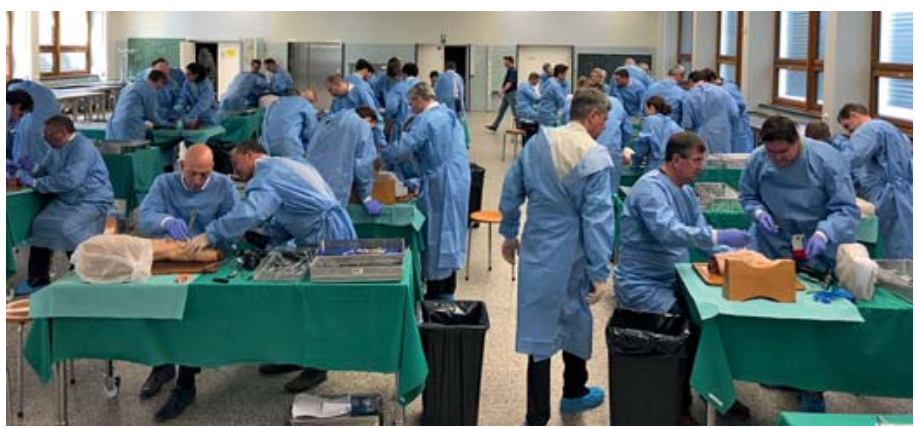

Abb. 1 Anatomische Übungen.

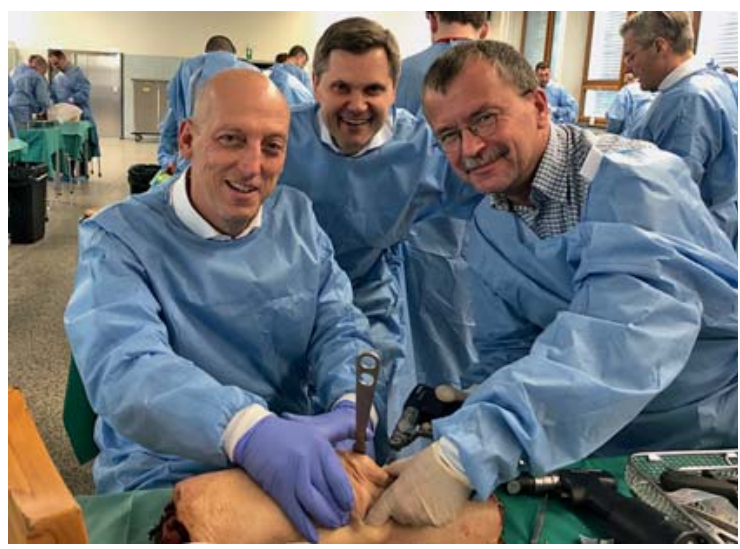

Abb. 2 Karl-Dieter Heller, Karl-Heinz Frosch und Eckhard Priepke.

DOI https://doi.org/10.1055/a-0647-2659

OP-JOURNAL 2018; 34: 191 @ Georg Thieme Verlag KG Stuttgart · New York ISSN 0178-1715 